\title{
Biomass combustion and potential health effects in the developing countries
}

\author{
Joshi SK ${ }^{1}$, Dahl A ${ }^{2}$, Kristensen $\mathbf{T}^{3}$, Roldin $\mathbf{P}^{4}$ \\ ${ }^{1}$ Department of Community Medicine, Kathmandu Medical College, Sinamagal, Nepal, ${ }^{2}$ Ergonomics and Aerosol \\ Technology, Lund University, Sweden, ${ }^{3}$ Department of Chemistry, University of Copenhagen, Denmark, ${ }^{4}$ Division of \\ Nuclear Physics, Lund University, Sweden
}

$\mathrm{B}$ omass combustion is a very large source of aerosol particles on a global scale. It is estimated that $20 \%$ of the black carbon and $30 \%$ of the organic carbon aerosol mass emissions are due to wild land fires and intentional burning of agricultural waste in Asia. However in those numbers residential fuel combustion is not included, which is considered a larger source of black carbon and organic carbon aerosol particles in developing countries. When it comes to residential fuel combustion it covers combustion of coal, kerosene, gas and biofuel in stoves, cookers and heaters ${ }^{1}$. In regions where the climate forces people to preserve heat in their houses, food is often cooked over open fire indoors. The hot emissions from the fire are then directly used to heat the house, instead of using a heat exchanger such as a chimney. When wood or coal is used as fuel the particle concentration indoor reach hazardous levels. Especially women and their small children are exposed to the emissions, since they spend much time inside and often close to the fire place ${ }^{2-7}$. This article elucidates the health effects related to biomass combustion in developing countries with focus on aerosol particles and the current knowledge in this field.

Chemical and physical properties of biomass combustion aerosols

It is hard to characterise the chemical and physical properties of the aerosol from biomass combustion in general since it depends on the regional composition of the biomass, the temperature of the combustion and the amount of oxygen available for the process. In addition the aging of the aerosol particles depends on ambient conditions. For instance the condensation or evaporation of semi-volatile organic and inorganic vapors are strongly temperature and concentration dependant, and the lifetime of the nucleation and Aitken mode particles will depend on the coagulation sink of the background aerosol. To shed some light on this topic, focus will be on situations where people are exposed to the aerosol close to where the biomass combustion takes place e.g. in homes during cooking and heating. In the developing countries solid fuel is dominating in the households and consists primarily of wood and agricultural residues $^{8}$. It can be seen from fig. 1 that use of solid fuel dominates in developing countries such as India, Afghanistan, Bangladesh and most African countries. The airborne particle mass concentration, measured as total suspended particulate matter (TSP), in households with open fire is often in the order of milligrams per cubic meter. As reference, the occupational TSP limit in Sweden is $5 \mathrm{mg} / \mathrm{m} 3$.

Wood consists primarily of the two polymers cellulose (50-70\% by weight) and lignin $(\sim 30 \% \text { by weight })^{9}$. In addition organic compounds with low molar mass and inorganic salts are present in wood. During combustion, pyrolysis occurs and the polymers break apart and produce a variety of smaller molecules. If the combustion is very efficient most of the carbonaceous matter will be transformed into $\mathrm{CO}_{2}$. However wood combustion in homes is seldom efficient and lots of partially oxidised organic compounds will be present both in the particle and gas phase.

To investigate the physical composition of the aerosol people are exposed to, measurements should ideally be performed in the households. A study conducted in the households in Costa Rica during cooking period revealed that a stack was connected to the stove where wood was combusted ${ }^{10}$. A typical mass size distribution of the measured aerosol particles with two modes can be seen in fig 2 .

With regard to health impact it is probably of high relevance also to investigate the particle number concentrations down to $\sim 10 \mathrm{~nm}$ since the smallest particles are efficiently deposited in the lungs and may

Correspondence

Dr. Sunil Kumar Joshi

Associate Professor

Department of Community Medicine

Kathmandu Medical College

E-mail: drsunilkj@gmail.com 


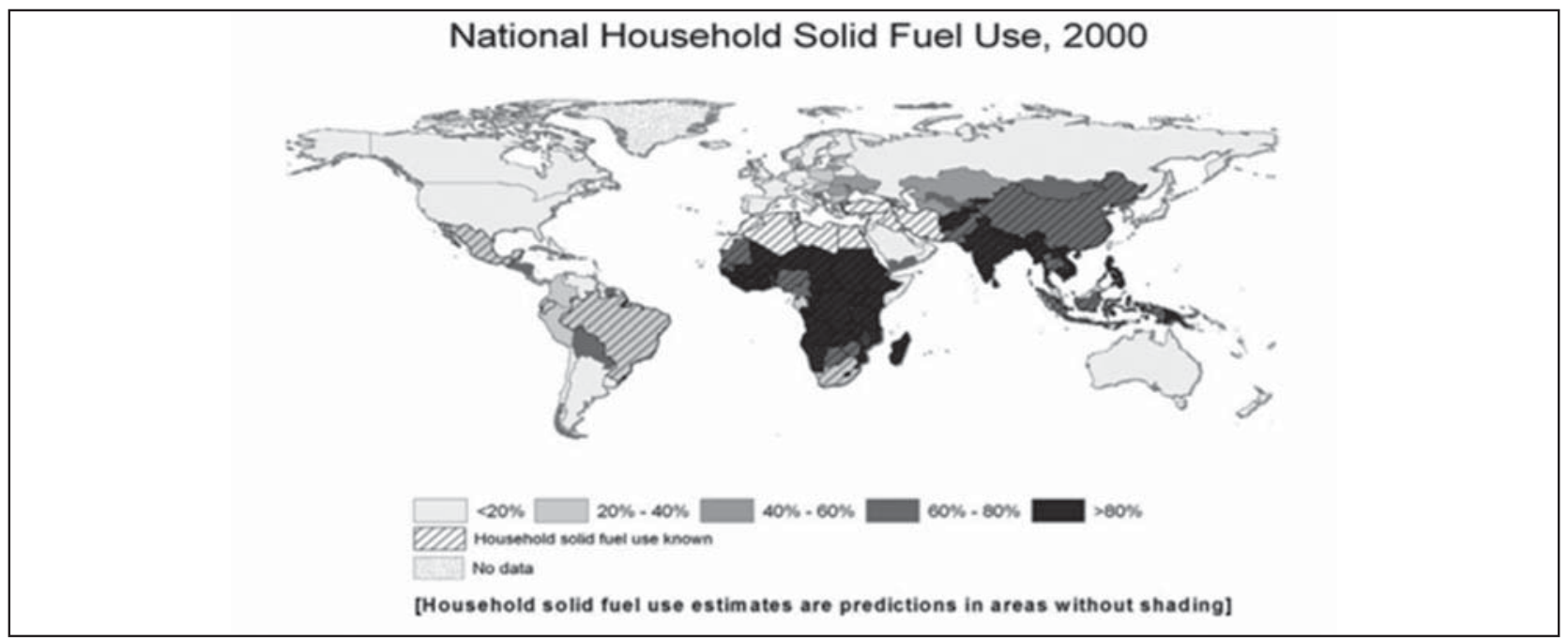

Fig 1: Map of solid fuel use ${ }^{2}$



Fig 2: Size distribution of aerosol particles in Costa Rican rural households measured with an Aerodynamic Particle Sizer (APS) $)^{10}$



Fig 3: Particle number size distribution from birch wood combustion with a stove. Circles indicate average values and the solid line median values. 90 - and 10 - percentile covered by the gray area ${ }^{12}$ 
reach all the way to the alveoli ${ }^{11}$. A typical particle number size distribution from birch wood combustion in a stove can be seen in fig. 3. There seems to be a (broad) maximum in the number concentration for diameters around $50 \mathrm{~nm}$ but with lots of smaller particles present. It is however questionable how much this size distribution resembles the combustion in open fire places in homes in developing countries. Often the fuel is combusted under poor conditions. In many households in the developing countries there is no stack or chimney. This will lead to a larger fraction of bigger aerosol particles and due to the large coagulation sink probably to less smaller particles.

To assess the health effects of the aerosol particles it is also necessary to know the chemical composition. The chemical composition is very important with regard to toxicity of the particles. Most wood combustion in homes will lead to production of soot in the particle phase. In addition to soot a great variety of organic compounds will be present in the particle phase. Among the organic compounds that can be found in the particle phase are the Polycyclic Aromatic Hydrocarbons (PAHs) that are known to be mutagenic and carcinogenic. Among the multitude of oxygenated organics are the phenols found in the particle phase. Several of the phenols are known to be irritant, carcinogenic, mutagenic and teratogenic. In addition inorganic elements (e.g. $\mathrm{KCl}$ ) are often present in the particle phase ${ }^{2}$. These salts will make the particles grow to larger sizes when exposed to high relative humidity in the lung, and thereby affect the deposition probability of the particles. Apart from the particles the bio-mass smoke is reported to contain a large number of harmful gas phase species, mainly carbon monoxide (CO), Sulfur Dioxide $\left(\mathrm{SO}_{2}\right)$, Oxides of Nitrogen $\left(\mathrm{NO}_{\mathrm{x}}\right)$, Ozone $\left(\mathrm{O}_{3}\right)$, Formaldehyde $(\mathrm{HCHO})$ and $\mathrm{PAHs}^{14}$.

Techniques for health relevant particle characterisation and exposures

The reference method for measuring airborne particles mass concentration is filter sampling. Often filter sampling is replaced by light scattering instruments, because it provide less labor intense handling. One serious problem with light scattering techniques is that they must be calibrated to the target aerosol. Therefore less skill demanding methods, such as filter sampling, probably are more robust and less prone to error.

\section{Observed health effects}

Biomass smoke exposure increases the diseases such as Acute Lower Respiratory Illness (ALRI) in childhood (pneumonia); Asthma, Chronic Bronchitis (CB); and Chronic Obstructive Pulmonary diseases (COPD); etc. in children and adults ${ }^{13}$. The pollutants from the biomass smoke cause inflammation of lungs, reduce ciliary clearance, and impair immune response $\mathrm{e}^{15}$. Similarly, particulate matter, gaseous pollutants, and other chemicals present in the indoor air may cause damage to nasal olfactory and respiratory mucosa ${ }^{16}$. Exposure of pregnant women to high level of CO may cause intrauterine growth retardation of the foetus ${ }^{17}$. There are evidences that exposure to ultrafine particles may lead to development of cardiovascular diseases ${ }^{18,19}$. Housewives and small children, who stay in front of the fire, for even a short period of time, are potential targets for serious health outcomes in the long run. Exposure to $\mathrm{CO}, \mathrm{O}_{3}$ and $\mathrm{NO}_{2}$ are known to be asphyxiant and irritants respectively. Whether there is reason to expect synergistic effects together with aerosol particles is not well investigated.

\section{Biological mechanisms}

There are several mechanisms anticipated to elucidate the adverse health effects of particles. It has been assumed that exposure to particles lead to inflammation, cytokine and chemokine release, production of white blood cells, production of oxygen free radicals in the lungs leading to endotoxin mediated cellular and tissue responses, stimulation of irritant receptors and covalent modification of key cellular enzymes. PM exposure is likely linked to inflammation through the generation of reactive oxygen species and oxidative stress. It is still not clear which particle components are responsible for producing reactive oxygen species, but there is increasing evidence that pro-oxidative organic hydrocarbons, such as polycyclic aromatic hydrocarbons, quinines, and transition metals such as copper, vanadium, chromium, nickel, cobalt and iron have important role $\mathrm{e}^{20,21}$. Those reactive oxygen species can damage cellular proteins, lipids, membranes, and DNA. In order to prevent this damage, cells utilise stored up antioxidant such as glutathione. Depletion of glutathione can induce a state of cellular stress, called oxidative stress. Such an oxidative stress can increase the production of antioxidant enzymes through activation of a transcription factor $\mathrm{Nrf}^{22}$. If the organism fails to overcome oxidative stress, it leads to the activation of additional intracellular chemicals that regulate the expression of cytokine and chemokine genes ${ }^{21,23}$. These cytokine and chemokine are produced locally in target tissues as well as systemically, and initiate widespread pro inflammatory effects.

\section{Control measures}

There is a large need for improved technologies and education in developing countries to be able to reduce the exposure to biomass combustion in indoor environments. Actions that can improve the situation are better ventilation, stoves, fuels and behaviour changes ${ }^{24}$. Most research has focused on how to make the stoves more efficient and emit less smoke. However 
there is also a need to study the actual conditions at which the stoves are operated. Often the conditions are far from optimal and the gain which better technology may not be as good as it could be ${ }^{25}$. Another action that is believed to have large potential benefits is to shift fuel from unprocessed biomass fuels to charcoal ${ }^{25-26}$. It would be even better, in a health perspective, if the solid fuels were replaced with nonsolid fuels. However this is not likely within the near future ${ }^{25}$.

\section{Conclusions}

Although the biological mechanism that can explain the health effects related to PM exposure is not well known there are a large number of studies which has linked severe health effects to PM exposure from biomass combustion in indoor environments. These findings should be more than enough to perform control measures to improve the indoor environment in developing countries. It can also be argued against the necessity to conduct field measurements when particle levels are clearly hazardous, but different governmental programmes targeting the health of poor people compete against each other. Pure water and disease prevention often catches most attention, as acute effects are more obvious to the public and policy makers. Poor indoor air is a problem that the exposed population has lived with for generation and therefore the problem is not clearly noticed. It is therefore important to conduct field measurements even if the results are obvious. Especially measurement should be conducted in conjunction with programmes on indoor air improvements, in order to observe and quantify the effects. Research has been focussed on technological improvements of stoves and chimneys however little attention has been drawn on how the technologies are implemented in the homes. In developing countries the most vulnerable groups are generally children and women who spend much of their time indoor preparing the food. We should address the need for research on cost-efficient technologies which improve the indoor environment, especially during cooking which generally cause the highest PM exposure levels. This together with education of women and children has the potential to save hundred thousand of lives every year in the developing countries.

\section{References}

1. Streets DG, Bond TC, Carmichael GR, Fernandes SD, Fu Q, He D, Klimont Z, et al. An inventory of gaseous and primary aerosol emissions in Asia in the year 2000. Journal of Geophysical Research. 2003;108: D21.

2. Naeher L, Brauer M, Lipsett M, Zelikoff J, Simpson C, Koenig J, et al. Woodsmoke health effects: a review. Inhal. Toxicol. 2007;19:67106.
3. Davidson C, Lin S, Osborn JF, et al. Indoor and outdoor pollution in the Himalayas. Environ Sci Technol. 1986;20:561-7.

4. Balakrishnan K, Parikh J, Sankar S, Padmavathi $\mathrm{R}$, et al. Daily average exposures to respirable particulate matter from combustion of biomass fuels in rural households of Southern India. Environ Health Perspect. 2002;110(11):106975.

5. Menon P. Indoor spatial monitoring of combustion generated pollutants by Indian cook stoves. Honolulu: University of Hawaii; 1988.

6. Saksena S, Sing PB, Prasad RK, Prasad R, Malhotra P, Joshi V, et al. Exposure of infants to outdoor and indoor air pollution in low-income urban areas: A case study of Delhi. J Expo Anal Environ Epidemiol. 2003;13(3):219-30.

7. Fullertona DG, Bruce N, Gordona SB. Indoor air pollution from biomass fuel smoke is a major health concern in the developing world. Trans $\mathrm{R}$ Soc Trop Med Hyg. 2008;102(9):843-51.

8. Smith KR, Mehta S, Maeusezahl-Feuz M. Indoor smoke from household solid fuels. In comparative quantification of health risks: Global and regional burden of disease due to selected major risk factors. Ezzeti M, Rodgers AD, Lopez AD, Murray CJL, editors. Geneva: World Health Org; 2004.p.1435-93.

9. Simoneit BRT, Schauer JJ, Nolte CG, Oros DR, Elias VO, Fraser MP, et al. Levoglucosan a tracer for cellulose in biomass burning and atmospheric particles.Atmos. Env. 1998;33:17382.

10. Park E, Lee K. Particulate exposure and size distribution from wood burning stoves in Costa Rica. Indoor air. 2003;13: 253-9.

11. Löndahl J, Pagels J, Boman C, Swietlicki E, Massling A, Rissler J, et al. Deposition of biomass combustion aerosol particles in the human respiratory tract. Inhalation Toxicology. 2008; 20: 923-33.

12. Hedberg E, Kristensson A, Ohlsson M, Johansson C, Johansson PA, Swietlicki E, et al. Chemical and physical characterization of emissions from birch wood combustion in a wood stove. Atm. Env. 2002; 36:4823-37.

13. Fullertona DG, Bruce N, Gordona SB. Indoor air pollution from biomass fuel smoke is a major health concern in the developing world. Trans $\mathrm{R}$ Soc Trop Med Hyg. 2008;102(9):843-51.

14. Smith KR. Biofuels, Air Pollution, and Health: A Global Review. New York: Plenum Press; 1987. 
15. Bruce NG, Perez-Padilla R, Albalak R. Indoor Air Pollution in Developing Countries: A Major Environmental and Public Health Challenge. Bulletin of the World Health Organization. 2000;78(9):1078-92.

16. Calder'On-Garcidue Nas L, Azzarelli B, Acuna H. Air Pollution and Brain Damage Toxicologic Pathology. 2002;30(3):373-89.

17. Boy E. Bruce NG, Delgado H. Birthweight and Exposure to Kitchen Wood Smoke during Pregnancy. Environmental Health Perspectives. 2002;110(1):109-14.

18. Pope CA III, Hansen ML, Long RW, Nielsen KR, Eatough NL, Wilson WE, et al. Ambient Particulate Air Pollution, Heart Rate Variability, and Blood Markers of Inflammation in a Panel of Elderly Subjects. Environmental Health Perspectives. 2004;112(3):339-45.

19. Miller KA, Siscovick DS, Sheppard L, Shepherd K, Sullivan JH, Anderson GL et al. Long-term exposure to air pollution and incidence of cardiovascular events in women. N. Engl. J. Med. 2007;356:447-58.

20. N Li et al. Ultrafine Particulate Pollutants Induce Oxidative Stress and Mitochondrial Damage. Environ. Health Perspect. 2003;111: 455.
21. Silbajoris R, et al. In vivo and in vitro correlation of pulmonary map kinase activation following metallic exposure. Inhal. Toxicol. 2000;12:45368.

22. N. Li et al. Is a Key Transcription Factor That Regulates Antioxidant Defense in Macrophages and Epithelial Cells: Protecting against the Proinflammatory and Oxidizing Effects of Diesel Exhaust Chemicals. J. Immunol. 2004; 173:3467-81.

23. Xiao GG et al. Use of Proteomics to Demonstrate a Hierarchical Oxidative Stress Response to Diesel Exhaust Particle Chemicals in a Macrophage Cell Line. J. Biol Chem.2003;278:50781-790.

24. Smith KR. Indoor air pollution in developing countries: recommendations for research. Indoor Air. 2002;12:198-207.

25. Ezzati M, Kammen DM. The Health Impacts of Exposure to Indoor Air Pollution from Solid Fuels in Developing Countries: Knowledge, Gaps, and Data Needs. Environmental Health Perspectives. 2002;110(11):1057-68.

26. Ezzati M, Kammen DM. Quantifying the Effects of Exposure to Indoor AirPollution from Biomass Combustion on Acute Respiratory Infections in Developing Countries. Environmental Health Perspectives. 2002;109(5):481-8. 